\title{
SELLING EBOOKS TO THE HOME SCHOOL MARKET ${ }^{1}$
}

John and Helen Farrell faced a major turning point in their business. For the previous 6 years, their consultancy had been developing content for the clients of a major broker, making them a business-tobusiness (B2B) supplier. Originally, that content had been dominated by traditional media types, such as DVDs, audio books, and printed materials. Subsequently, their focus had gradually changed to mobile devices. Recently, however, health issues, a weak economy, and competing educational commitments had forced them to terminate the relationship, at considerable personal expense. Without that captive marketing relationship, their business had become far more risky. On the other hand, if they were successful, the potential for profit was correspondingly greater.

Without a contractual marketing partner, the Farrell's had considerably more choices with respect to the types of content they would produce, the content-creation technologies they could employ, the types of distribution channels that they could use, and the method by which they produced their final product. Only the first of these choices had been more-or-less finalized: they intended to focus on providing mobile education content directly to consumers (B2C). Not only did this leverage off of their existing skills and the library of educational content that they already owned, it also represented one of the fastest growing markets in publishing. The remaining choices were much more complicated. These included:

1) What devices to support. Choices included iPads, iPhones, Kindles, Nooks, Android phones, and tablets, or all of the above. Device choice, however, had significant channel implications since each device was associated with a particular marketing and distribution system (e.g., iTunes, Android Marketplace, Amazon).

2) Whether to deploy full blown apps or interactive ebooks. This decision could not be made independent of device. As customized apps grew more complex, it became increasingly expensive to migrate from one device to another, raising the cost of a multiple device strategy.

3) Whether to author their apps and ebooks natively or use packaged authoring solutions. Authored apps provided greater flexibility, but were much more expense to produce.

4) Whether to target schools, private individuals, or school alternatives such as the homeschooling market.

Whatever decision they reached, they needed to do it quickly. They had already used most of their cash reserves to sever their former B2B contract.

\footnotetext{
${ }^{1}$ Copyright $($ 2012, Informing Science Institute. This case was prepared for the purpose of class discussion, and not to illustrate the effective or ineffective handling of an administrative situation. Names and some information have been disguised. Permission is granted to copy and distribute this case for non-commercial purposes, in both printed and electronic formats. This material is based upon work supported by the National Science Foundation under Grant No. 1043919.
} 


\section{Electronic Publishing Industry}

The age of publishing began in 1440, when Gutenberg invented the first printing press. For hundreds of years after that, however, the principal market for books remained relatively small, limited to the small number of individuals who were both reasonably well-to-do and literate. In 1971, a new era within that age began. In that year, the Gutenberg Project, which focused on digitizing important books whose copyrights had expired, was launched. Over its lifetime, that project translated tens of thousands of books into ASCII-formatted text. But, like its paper predecessor, its practical impact took a long time to be felt. While literacy and wealth was no longer a major stumbling block, few people wanted to read entire books on their computer. Not to mention the fact that for the first 10 years of the project, almost nobody had a computer.

Over the twenty years from the mid-1980s to the mid-2000s, electronic publishing grew in fits and spurts, although generally advancing far slower than predicted. A number of technologies enabled this growth:

- In the late 1980s, CD technology made it possible to deliver books with embedded multimedia. An early example of a "book" delivered in this format was Compton's Multimedia Encyclopedia (1989). Microsoft's Encarta, introduced in 1993, became the biggest seller in this market.

- In the early 1990s, the widespread adoption of MS-Windows Version 3 made graphic user interfaces ubiquitous. While such interfaces had been developed much earlier-e.g., at Xerox Palo Alto Research Center in the late 1970s and in Apple's Lisa and Macintosh computers in the mid1980s, as well as earlier versions of MS-Windows introduced in the second half of the 1980s - it was not until the early 1990s that Windows became the standard. From a publishing standpoint, Windows meant that anything that could be delivered on the page could similarly be displayed on the screen.

- Technologies that allowed documents to be printed to a screen-viewable file were introduced. Most notably, Adobe Acrobat - which created files using the same PostScript language used by many high-end graphic printers - was introduced in 1993 and became the de facto standard for exchange of electronic screen-readable documents.

- The rapid growth of the Internet in the late 1990s made the transfer of eBooks much more efficient than mailing CDs back and forth.

Despite all these technological advances, eBooks penetration remained little more than a rounding error in the global publishing market during the 1990s and through the first five years of the new millennium. The problem remained the same: there was little enthusiasm for reading books off a computer screen.

\section{eBook Readers}

In 2004, new technologies were introduced that began the transformation of the electronic publishing world. The Sony LIBRIé might be described as the world's first modern eBook reader. It was small, light and used eInk technology that made it much easier on the eyes than a computer screen. What it lacked, however, was a distribution system for content. Ultimately, the product failed to gain traction. What it did do, however, was to awaken the world to what was now possible. That led to the introduction of the Kindle eBook reader by Amazon.com in 2007. Outwardly somewhat similar to the Sony model, it differed in two very important ways:

1. It incorporated communications technologies that facilitated the acquisition of eBooks, both cellular and wireless. 
2. It seamlessly integrated with Amazon's traditional printed book website, creating an easy way to find and pay for eBooks. As a further advantage, Kindle versions of books tended to be priced cheaper than their printed counterparts.

Although it took a couple of years for the Kindle to gain traction, by 2012 the various Kindle devices had become the most widely sold products by Amazon.com and, in 2011, Amazon's eBook sales surpassed printed sales.

Witnessing the success of the Kindle, competitors and technology did not stand still. At Apple, the popular iPod product that had resurrected the nearly failing company introduced a screen that was large enough to make reading possible. That meant that eBooks could now be distributed through the same closed iTunes infrastructure that was used to deliver audio and video. New devices, such as the $i$ Phone and - particularly - the iPad were even better suited for this purpose, offering color and multimedia capabilities as well as a comfortable reading device. Other publishers, such as Barnes and Noble, offered their own sales infrastructure and associated device, the Nook.

Google, the largest Internet player, was not unaware of these developments. In fact, because of its need to search for information, it had already embarked on a project to digitize virtually all books. Although the legal system had presented numerous obstacles to this plan - supported by some copyright holders-it increasingly offered digital book content through Google books. On the device site, it offered the Android operating system, a largely open source alternative to Apple's iOS, Microsoft's Windows, Linux and other operating systems that could be used on cell phones, tablet devices, and computers. An interesting convergence occurred when Amazon.com used a variation of Android to power the marketplace for its new Kindle Fire, an inexpensive color multimedia device offering a suite of capabilities similar to the iPad.

By 2012, the publishing industry was experiencing turbulent — and often painful — changes. Major distribution networks - most notably iTunes and Amazon - were experiencing legal challenges from publishers with respect to their pricing policies. The very idea of traditional publishing was being threatened. Historically, book publishers had always performed three roles:

1. Quality Control: They screened books and authors, rejecting works that they perceived insufficiently worthy.

2. Production: They took the book from manuscript to printed form.

3. Marketing and Distribution: They provided publicity for books and arranged to get them into bookstores.

All three of these activities were now under siege. While quality control and editing continued to be the publisher's most critical function, crowd-based evaluations - such as the reviews on Amazon and "Like" button on Facebook - now provided an alternative way for potential readers to make selections. While most self-published works languished, a few were breaking out. Since publishers themselves had only limited success in judging the merit of works - the vast majority of published works lose money - this alternative approach to evaluation represented a major threat.

The production activity had become increasingly irrelevant. Traditionally, typesetting and printing had represented major fixed costs associated with publication. For the past several years, however, sites like Amazon's Booksurge had made it possible to produce short run printed versions of books for substantially less than it cost to make multiple copies at the local copy center. And, of course, no printed copies whatsoever were required for eBooks. 
Marketing and distribution functions were also threatened by the major web players, most notably Amazon.com and iTunes. These sites eliminated the need to sell products into bookstores. Indeed, they had already been successful in putting major brick-and-mortar booksellers such as Borders out of business. While it was easy for a book to get lost in the millions of titles offered by Amazon.com, once you knew what you were looking for there was never any issue of where to find it.

Beyond these, the growing convergence of smartphone, tablet, and eBook reader capabilities made it increasingly difficult to distinguish where a book ended and where an application began. It was addressing this issue that was of particular importance to the Farrells.

\section{eTextbooks}

A unique segment of publishing was the $\$ 12$ - \$14 billion textbook market, commonly used in the U.S. from kindergarten all the way to graduate school. It differed from other channels in that the end-consumer does not have the same advantages of product-selection between competing brands, as (in the majority of cases) the choice of required textbook was usually dictated to students by the curriculum of their classes, which is often determined at the school system or university level. Another key difference of textbooks was that they tended to be reused. This took place in two ways. In school systems, a particular textbook might be purchased and passed down from class to class for up to 10 years. At the university level, students would sell their textbooks back to bookstores or other vendors. As a consequence, at least in the purchaser's mind, the cost of a textbook was not the same as its purchase price. As a result, prices for textbooks had remained high even in the face of technological changes that would have been more disruptive in other industries. Nevertheless, particularly in higher education, considerable pressure had been building to bring textbook costs back under control.

In January 2012, however, Apple declared war on the textbook industry by releasing iBooks Author. This was generally considered a sign that more platforms lowering the cost of entry into publishing educational apps and interactive books were going to be released. The expected result would be both increased opportunity and increased competitiveness in the industry. Apple's iBooks platform and associated body of eBooks have been expanding ever since the initial announcement of the iBooks app in the first quarter of 2010. It was expected to expand even further as a result of the free authoring software, the design of which was particularly influenced by (but certainly not limited to) use for textbook creation. At the same time that Apple's presence has the potential to lower existing textbook prices, the U.S. Justice department was threatening to sue Apple and the top 5 American publishers for price-fixing in the textbook eBook publishing space. Interestingly, Steve Jobs mentioned prior to his death of his dream of making textbooks free.

Apple was not alone in focusing on textbooks. A dedicated Kindle Textbook rental program had been initiated, allowing a digital textbook to be distributed to any Kindle-software enabled device (e.g., Kindle devices, computers with the Kindle eBook reader software, iPhones with Kindle app installed). The textbook was then made available for a set period of time between thirty days to a year, after which the digital asset expires from the user's Kindle collection. The price of textbook rental was consequently far lower than textbook purchase price, as much as $80 \%$ off the list price. Another very interesting feature of this rental program was that the student could keep any notes taken with Kindle software, even after the rental of the textbook expired.

Barnes and Noble introduced its own program for its competing Nook marketplace called Nook Study, which offered discounted textbook eBooks for computers (not the Nook device itself, which is noteworthy) with the Nook e-reader software. It provided similar text highlighting and note taking features to the Kindle offering and allowed for limited copy and printing of critical pages, as well as dual view ability to 
read more than one book at a time for comparative readings. eTextbook rental was also available through this program.

Students could benefit from the features unique to an eBook that would not be available in print form (availability across devices and machines, with preserved notes, etc). However, price differential was likely to be the driver for most eTextbook purchases. According to eCampus.com, at least $40 \%$ of the students surveyed in their study responded that "lower price" was the main attraction to the medium, with only $25 \%$ listing "instant access" and 19\% listing "portability".

\section{eBooks and Apps for the Homeschool Market}

Particularly at the elementary and secondary school levels, the ability of individuals and small firms to create and market textbooks or eTextbooks was limited. Textbook were normally selected by school boards, typically from the offerings of large publishers. In some states, such as Texas, the selection was state wide. As a consequence, the markets considered most promising by the Farrells were for supplemental materials acquired by parents on their own and, most critically, the homeschool market.

Once upon a time homeschooling was an option exercised by families of one particular religion or another in the hopes that they could teach that religion as part of their curriculum. That was no longer the case. According to the National Home Education Research Institute (http://www.nheri.org):

Homeschooling - home education or home-based education - has grown from nearly extinct in the United States in the 1970s to now about 2 million school-age students. Much research is being done, internationally, on this fast-growing form of education.

Studies indicated across the board increases in homeschooling across every nationality, every religion, and even household income brackets.

There were a number of factors driving the homeschooling movement. One of the key parental concerns was the curriculum. One group of parents - including much of the religious segment-were concerned by the exclusion of faith and other values-based learning in the public schools. Another overlapping segment was concerned that the curriculum was becoming too narrow. Mandates such as "No Child Left Behind" had forced schools to focus increasingly on improving test score in core areas. Particularly in mathematics and science, this approach had produced some improvements over time - contrary to much popular wisdom. Nevertheless, it came at the cost of cutbacks in areas such as art, music, reading, and even recess. Finally, many parents felt that the special needs of their children were not being addressed within the school system. Such parents often felt that homeschooling was the most cost-effective means of addressing this problem, frequently linking up with other parents as students got older to provide for the social needs of their children and to bring in broader expertise across subject areas. According to an article written in 2003 by home schooling expert Mark Lardas, parents of homeschooled children typically spent between $\$ 600$ and $\$ 700$ per year on each child homeschooled for educational material in that year, a number likely to be substantially higher by the time of the case.

\section{Apps Versus Interactive eBooks}

Educational apps and eBooks shared the same set of devices, namely: the iPad, the Kindle Fire, and the Barnes and Nobles Nook. eBooks, however, had slightly different distribution platform offerings from Apple and Amazon and were known to have more flexible approval policies.

There were many similarities between eBooks and apps. Both provided valuable features for content creators to digitally create and distribute electronic versions of their content. Both offered a means of experiencing media on portable electronic devices or even stationary computers, and both often benefit from 
wireless distribution to devices. Both had several marketplaces dedicated to distributing their respective content types, some of which worked across different device types, and some (such as Apple's) catered to one company's devices.

\section{Structural Differences}

There were also some differences between the two categories. Typically, eBooks were constructed as a digital representation of books, with primarily linear flow of text-dominated content. An eBook traditionally might be a novel, a textbook with limited interactive features, a comic book, a cookbook, or almost anything that might have been a book before the electronic content age. eBooks also tended to be based off HTML and similar technologies, wrapped in a container file format like .EPUB or mobi or PDF. Historically, eBook features were kept to a minimum of complexity to accommodate broadest possible device compatibility. For this reason, multimedia-rich features were avoided so that a first generation Kindle user (or other early eBook reader) would be able to access the content. That situation was changing, however. More and more, eBooks were being released with greater interactivity, as eBook readers progressively overlapped the tablet category. For example, Amazon's Kindle Fire, originally priced at \$199, offered a high quality tablet experience with multimedia playing features as well as Internet and app store access. It was the first Amazon Kindle device to support the KF8 file format, which takes advantage of the emerging HTML5 and CSS3's standards. These standards were important because they supported many of the multimedia and interactivity features once available only in proprietary technologies such as Adobe Flash. While content created using these features would not work earlier dedicated eBook readers, there seemed little doubt that they would soon be supported by nearly all future devices, including those at a low price point.

Apps on the other hand, ran natively on a targeted device, providing access to a much wider set of features (e.g., GPS, databases, and text messaging) and typically went through a more rigorous - and therefore expensive-development process. Apps were often built around an event-driven, nonlinear model more reminiscent of a software application than a book. Apps, like eBooks, could also certainly be organized according to a linear flow; they simply weren't constrained by that flow.

\section{Development Differences}

All other things being equal, eBooks tended to be simpler and less expensive to create than apps. Depending on the content, developing a viable eBook could be as simple as taking the source content in a .doc and running it through brand-specific tools. For example, Amazon.com provided a tool for converting an MS-Word document to the .azw format used by the basic Kindle. There were also third-party conversion tools, some of which were open-source, such as Calibre and Sigil. These tools, however, were not normally capable of supporting more interactive HTML5-based eBook functionality.

Apart from the limitations of more automated conversions, competent creation and customization of eBook content could be accomplished with HTML technologies, or even with graphical WISYWIG (what you see is what you get) editors such as Adobe's InDesign (or even Dreamweaver). Additionally, Apple's recent release of the iBooks Author program provided the layperson with an extraordinarily easy-to-use (if somewhat restricted) program to create multimedia rich eBooks which could be submitted to the iBooks store. There was be a bit of a training curve in terms of ensuring quality and control of the desired presentation with regards to pictures and other multimedia content across both portrait and landscape orientation, but even that could be managed by specifying that the eBook be limited to the more multimediafriendly "landscape only" orientation. In that scenario, a competent user of desktop publishing or word processor programs (Microsoft Word, PowerPoint, etc.) could make a relatively painless transition to the iBooks Author program. 
To summarize, app programming almost always requires actual programming in a specific environment with specific skill requirements, whereas eBook creation can (in most common cases) be accomplished in fully to partially automatic means if the user is at least competent in Microsoft Word. But, both apps and eBooks can display text, audio, video, and even interactivity to the user with the latest eBook formats. So, the line between a native app and an eBook is further blurred every day.

\section{Distribution Differences}

There were also some distribution differentiation between apps and eBooks. The most obvious difference in terms of distribution between apps and eBooks was that apps could go onto portable smart devices such as an iPad, iPhone, or Android device, but could not be deployed on lower end reader devices such as the original Kindle devices and Sony readers. eBooks could be installed on dedicated reader devices or deployed on more powerful tablet computers, smartphones, portable devices, as well as on computers with the proper reader software or app installed. This software often supported several eBook formats.

The flexibility of eBook software and apps translated to somewhat less dependence on a particular distribution channel. Although each reader-vendor had its own distribution network-e.g., Kindle's eBooks came from the Amazon Kindle store, Barnes and Noble's Nook eBooks came from the Barnes and Noble Nook Store, Sony's devices purchase eBooks from the Sony eBook Library store - the files could be moved to devices with general purpose readers. Conversion between formats could be more problematic since digital rights management (DRM) software frequently blocked such efforts.

Apps, for the most part, were more constrained in terms of distribution. A branded app store could well be the only source for a particular device. For example, iPad and iPhone apps cannot be installed on Android tablet devices and vice versa, even with highly specialized third party hacking tools. The market for Android apps was more complicated; since versions of Android ran on many different devices, there tended to be a specific marketplace for Barnes and Noble approved apps that can be installed on the Nook Devices, without official compatibility with wider Android App markets, such as the Amazon Android App store.

Both apps and eBooks typically required approval before they could be distributed from the major online retailers. All apps needed to go through a specific, non-superficial testing and approval process before Apple, Amazon, and most other major app stores would sell them. A specific individual or team of individuals would actually test the app and compare it specified own user experience guidelines (Apple in particular has strict standards in this sense and publishes those standards explicitly). Generally speaking, rejection from Apple or Amazon would be accompanied with very explicit feedback about why exactly the app was rejected and what needed to change for approval. Even to submit an app for approval, a developer account had to be established that furnished seller information, including tax identification numbers. These became incorporated into a contract between the app developer and the app store. In the case of both Apple's app store and Amazon's app store, non-modified screenshots of the app and accurate marketing information had to be furnished for the app. An app would be rejected if substantial differences between the app and marketing materials existed. In addition, Apple would reject apps that they felt should be delivered as eBooks. In other words, an app that was text-dominated and provided predominantly linear presentation of information/media was unlikely to be approved.

For eBooks, the distribution and approval process tended to be more flexible and varied by vendor. Apple stated that it would reject any book that doesn't meet their approval standards, many of which are based on technical points. For example, authors should not artificially add extra spaces between text paragraphs and images needed to be sufficient quality and meet specific dimension requirements. They could also reject content for broken hyperlinks (or even links to illegal content or other content providers that competed with Apple). 
Amazon.com's Kindle Direct Publishing program allowed for self-publishing of eBooks on the Kindle marketplace, and, like Apple, reserved the right to reject eBook submissions. Rejection could occur with prejudice, but more often was the result of incorrectly formatted HTML within the eBook. Another issue that could trigger rejection, included suspected copyright infringement (in the event that the author does not immediately demonstrate ownership). There were fewer "decency" approval/rejection guidelines for the Amazon Kindle marketplace than for Apple's iBookstore, as more explicit materials are available in the Kindle store.

Barnes and Noble offered a program called PubIt that functioned in much the same manner as the Amazon Kindle self-publishing program, except that it was limited to US availability. An author of an eBook could independently submit content to the PubIt program to be approved or rejected after creating an account and furnishing their "...U.S. Bank Account, U.S. Credit Card, and a U.S. Tax ID, that are ALL tied to a U.S. address".

\section{John and Helen Farrell}

After graduating from college, John Farrell started out as a programmer in the early 1990s. By the mid1990s, he had married Helen and the two of them started a computer software consultancy servicing the healthcare market. That company grew to a couple dozen employees and did well enough that John was also able to invest in a fitness center and the associated commercial real estate with 3 partners. One of those partners managed a $\$ 32$ million family investment fund and enjoyed working with John. John was subsequently offered the opportunity to become a co-manager of that family investment fund. The Farrells then sold their software business and John became one of 3 co-managers of that investment fund.

Over the next few years, John and the other two fund managers grew that fund to around $\$ 50$ million in monies under management with a multi-year track record of subsequent wins. Helen took a position as the office manager for a local large law firm. Because of John's performance at the fund, he had developed a network of high net worth contacts and was receiving a lot of job offers.

After several years of growing the fund, John was offered a position by a $\$ 300$ million market cap public biotechnology company that had been one of the fund's investments. The job was too interesting to pass up and John took it. A year after starting with the biotechnology company, however, John was diagnosed with cancer that was generally terminal. He was told that his two year survival likelihood was about $20 \%$, and that during that time he would be on a chemotherapy regiment that would result in him being more in the hospital than out.

The Farrells had amassed sufficient savings such that the only compelling reason for either of them to continue working was that, should John survive, he would need health insurance-and once they left their jobs, their ability to purchase health insurance through COBRA would expire within 18 months. John knew he no longer could work 16 hour days and also he knew that he would frequently have to be hospitalized. That meant taking any normal job would be problematic. They therefore needed an opportunity for both of them to work primarily from home, in a business that would provide a group health insurance plan, where they could hire employees to perform the day-to-day duties. They opened a consultancy. They built and furnished a 2,500 square foot office building on property they owned, hired their employees, and began work. For the next 6 years their consultancy executed a business to business model that leveraged John's high net worth relationships. In this model, their consultancy serviced a large agency client, who in turn brokered the consulting company's services out as part of its services matrix to its client companies with large agent bases who had annual revenues between $\$ 50$ million to $\$ 2.5$ billion. Typically, the brokerage company would call upon the consulting company to provide outsourced and confidential start up, merger and acquisition, short-term CTO for hire, and new product development services to the broker company's clients. 
Over time, the consultancy spent more and more of its time providing digital content product solutions to the broker company's clients. The broker company was itself primarily a content producer and publishing house that specialized in providing corporate training and advertising print, audio, and video content to its clients, delivered on DVDs, CDs, books, magazines, brochures, and via television or cable channels. The Farrells soon came to believe that technology content distribution was going to be the key driver of their business in the near term. After their consultancy got up and running from a cash flow and operational perspective, John therefore enrolled in a doctoral program in information systems and subsequently, Helen enrolled in a doctoral program in educational technology.

On the health front, John miraculously survived - although the chemotherapy had significant side-effects. Doctors warned him that cognitive impairments were present and that these could get progressively worse, get better, or stay the same. He had further developed permanent peripheral neuropathies in his hands and feet that on bad days prevented him from driving or being able to hold things like pens in his hand for any length of time. Even as the consultancy's revenues, headcount, and margins grew, John's health continued to deteriorate. Helen grew more and more frustrated at both the increased demands on her time and her concern that John was still trying to put on a front rather than admit to his colleagues that he could no longer perform the mental tasks or the normal work days that were once typical for him. She constantly watched for his lips and fingertips to turn blue or for his hands to start uncontrollably shaking. At those times, she would need to inform him that he was over-exerting himself, since he preferred to ignore such warning signs himself. John would then need to lie down until the symptoms subsided, but always telling Helen to hide the severity of his condition from the other employees, their clients, and his academic contacts.

After several years of rapid growth, the effects of the economic recession that was in progress finally began to impact the Farrell's consultancy. They were forced to deliver more and more value to their clients, who were increasingly outsourcing more and more of their work rather than making internal investments with fixed costs. Both the consultancy's and the brokerage company's cash collection cycle grew longer and longer as the broker's clients delayed making payments. The business-to-business model was becoming progressively more difficult to service, and more risky from a cash flow perspective. As John recovered from the surgeries that replaced his hips with artificial joints, Helen found herself spending more and more of her time on servicing issues with the clients and managing the employees, who themselves were getting progressively more stressed out as hours grew longer and longer.

Finally, Helen spoke with John and stated that the cash collection issues required some sort of change in operations. She recommended that John take a leave of absence from the doctoral program, the consultancy, or both unless his health further improved. The two then met with the owner of the brokerage company and his executive team. They were informed that terminating the consulting company's contract with the brokerage company would require writing off about a half a million dollars in revenues. In practical terms, this meant that a considerable number of expenses that the consultancy company had already paid out in advance on behalf of the brokerage company would not be reimbursed nor recouped. It was clear that if the consultancy wrote off that much revenue, they would need to reduce headcount significantly and immediately. The Farrells were confident they could get their current employees employed with other local companies with almost no gap, however, given their employee's highly technical skills.

In the final analysis, the Farrells agreed that trying to continue servicing billion dollar companies while one of the partners was getting progressively sick and, at the same time, trying to complete a doctoral program was unsupportable. They decided to terminate the contract with the brokerage company, write off the revenues, have John complete his doctoral studies, and attempt to change the business model of the consultancy to one that focused on selling a product instead of a service. 


\section{Mobile App Market and Educational Apps}

The particular product segment that first intrigued the Farrells was educational content on mobile devices, an area the existed on the boundary of publishing and software. The mobile app market wasn't one that was expected to slow down anytime soon with projected revenue estimated to be at $\$ 38$ billion by 2015 according to industry expert Tina Barseghian. On its website, Apple claimed to have over 500,000 apps for their iPad tablet device and iPhone. Of these, it was estimated that 30,000 or more belonged to the education market. Many educational apps in that category were available for free, while most were priced in the $\$ 1.99$ - \$5.99 range.

The majority of top selling apps in the Education category targeted children (80\%, according to Barseghian). The number of educational apps targeted to preschool and elementary age children has increased from half in 2009 to almost three quarters in 2012. A Common Sense Media study reported that more than a quarter of all parents had already downloaded apps for children. Children of all age groups loved the iPad. Those that didn't have one wanted one.

Looking at this number in a different way, according to Nielson Company, $57 \%$ of families with tablet devices (such as an iPad) were downloading and using educational applications. The tablet was a useful device for parents. Many parents were using tablets to entertain their children while traveling, running errands, or doing chores around the house. It is an easy "go to" gadget because the presence of educational apps meant it relieved a lot of the guilt associated with just turning on the television or playing video games. Educational mobile applications tended to be engaging, so children enjoyed playing them almost as much as they enjoyed playing video games. Nielson Company data had also indicated that the app marketers should be focusing more of their efforts on apps for children.

Barseghian also stated that apps aimed at toddler and pre-school aged children were of particular importance. A child's natural instinct is to touch what they want. A computer requires the use of keyboard and mouse while the monitor displays what is happening. The child who had to figure out how to use the mouse and keyboard to manipulate the objects on the screen became frustrated. The touch screen on the iPad virtually eliminated this learning cure.

Determining which app to download can be a daunting task, however. A Google search for the "top 10 science apps", for example, returned thousands of results. They included anything from the top 10 science apps for teachers to the top 10 science apps for health and fitness. Fortunately, educational magazines and websites were writing articles to address the issue of which app is the right app. These articles typically listed the app name, price point, a brief explanation of user's experience, and the pros and cons of each app. One particular contribution to education apps was compiled by the Texas Computer Education Association (TCEA). The organization tested over 1,000 education apps and organized them by subject matter. It even color coded the various price points for these apps and stored their "1,000 Education Apps Organized By Subject \& Price" compilation as a Google doc for anyone to review. Some examples of these apps are presented in Exhibit 1.

\section{Educational Apps, LLC}

The new mobile app distribution platforms provided by the Apple App store and the various Android app stores allowed development shops like the consultancy to potentially switch their focus to providing educational apps directly to end customers rather than providing corporate education apps to businesses.

The Farrells very much liked the idea of building a recurring revenue model that targeted selling their own app content directly to end consumers, rather than trying to continue servicing billon dollar B2B clients on retainer or otherwise trading dollars for hours. Moreover, the consultancy had built several mobile 
apps for several large clients of the brokerage company. Given their growing interest and experience in educational settings, it made sense to investigate the possibility of switching their focus to making education apps.

\section{Prototype Issues}

Once the Farrells had terminated their contract with the brokerage company, John spent the next three months preparing for his doctoral comp exams, while Helen helped the current employees obtain new jobs and managed the remaining employees to build some prototypes of educational apps, at an additional cost of about $\$ 100,000$. They first researched Apps that function similar to workbooks for elementary school aged children and beyond, checking the library, bookstores, and the web for competing products and price points. They also created some prototype apps.

Their first prototype app was a kindergarten app covering some basic objectives that would need to be met before a student enters kindergarten. The first step was to have a meeting to determine and discuss the general concepts of their app. They decided on a workbook approach. As the app took form, they realized that graphic artists experienced in designing training for adults frequently did not 'get' the nuances of designing apps for children. For example, using underwear as the picture for the letter $u$ was a bad idea..."Let's switch that to umbrellas or unicorns please."

Future apps would need a different design process. The management team decided that it would be better for them to write out a page-by-page skeleton of what was expected to be in the final product. Then the graphic artists would complete a second version with rough artwork. Upon completion of the second version, the management team would provide feedback and criticism or approve as final. This proved to be a beneficial process. The graphic artists spent less time correcting and less time going down the wrong path. It also provided more opportunity to make improvements in the user experience. The graphic artists also expressed gratitude for improved process since it gave them superior guidance and more useful feedback of expectations.

\section{Platform Issues}

The Farrells also found that getting product into content delivery channels was far less straightforward than it sounded. Indeed, each has its own unique peculiarities. This was not totally expected, since they had considerable experience deploying enterprise apps for the iPad, iPhone, Kindle Fire, and the Barnes and Nobles Nook. Those were the same major channels that would be used for the educational applications they were producing. Yet they kept encountering obstacles when submitting consumer-targeted apps.

The first distribution channel they submitted applications to was Apple. Apple declined some individual apps that Apple felt should be consolidated into in-app purchase apps. The Farrells believed these decisions were not correct based on their targeted audience. For example, Apple wanted them to submit the same app for kindergarten, first, second, and third grade, and require each grade to be purchased from within that app as in-app purchases. So, Apple would accept the app for kindergarten and first grade but reject the apps for second and third grade based on the fact that the app was the same for all four and the only difference was content. Helen and John believed the consumers of these products would be more likely to purchase these apps targeted for one particular grade level, usually for the grade level of the end user. This more closely resembled the bookstore model. Unfortunately, the company was unable to sway Apple to their model. 
They then submitted the same applications to Amazon. Amazon declined some apps based on undocumented rules and restrictions. The rejections caused 90-180 day delays in bringing products to market. The rejection delays coupled with the development time caused further delay in positive cash flow.

As Helen and John arrived at the stage to release their products in final form, which would have included a heavy investment into marketing campaigns to support their launch, other challenges arose. They discovered that their Apple and Kindle direct to consumer app accounts were originally set up under a former employee's name and information not their company name and information. Interestingly, Apple support reported that they do not provide the ability to correct this type of account information. Further, Apple reported the company would need to remove all of their previously approved apps from the incorrect account and resubmit them to Apple so they could be re-evaluated and re-approved by Apple under a new account. Additionally, Apple's system would not allow the creation of a new company account for a formerly registered company, so various appeals to Apple had to be submitted. These issues resulted in another 90-day delay to complete the Apple appeals process. This complication caused further delay before cash collections could occur from Apple sales.

Account information corrections did not prove to be an issue with Kindle. They were usually corrected within the week. But, the Amazon distribution channel then presented a different roadblock. The Farrells were notified that their Kindle selling account had been shut down because of a complaint made about their company's Amazon seller's account. Ironically, the complaint related to an unopened Kindle that was sold after the post-headcount reduction equipment liquidation. Helen described the problem as follows:

Amazon suspended our seller and Kindle App Developer account because an unopened Amazon Kindle had a defective battery. When the end customer complained to Amazon (the selling portal), Amazon (the manufacturer) refused to replace the defective battery at no charge. Even after we gave the customer a full refund, this also resulted in an additional 90 day plus delay before eBook or app sales could occur through Amazon's distribution channel. Ironically both the customer and Amazon acknowledged the problem seemed to be a manufacturer's defect on an unopened Kindle, but this made no difference in preventing the delay.

The only distribution channel that presented no anomaly glitches in getting the products approved and cash remitted was Barnes and Nobles. Unfortunately it had the smallest revenue potential of the three based on market share.

The delays burned through an estimated $\$ 100,000$ in cash flow with no associated revenues coming in. Between the contract termination write-offs and the 180 days of stall, the Farrells had invested about $\$ 600,000$ without cash recovery in changing the business model of the consultancy. They began to wonder if they wouldn't be better off deploying their interactive content as interactive eBooks rather than as full blown apps to side-step the worst of the Apple and Kindle appstore business challenges.

The more the Farrells considered the market potential of eBooks compared to apps, the more intrigued they became about whether they consider deploying interactive books. In considering the decision, Helen Farrell prepared a series of tables that outlined key elements that needed to be considered:

- Exhibit 2 provides a summary of issues related to apps vs. eBooks and possible pricing strategies.

- Exhibit 3 provides brief summary of the current color-supporting app and eBook platforms.

- Exhibit 4 provides a summary of eBook publishing channels and production.

- Exhibit 5 provides a comparison of different authoring tools. 


\section{The Decision}

In considering how to move forward, the prototype experience has taught the Farrells an important lesson: their distribution partners (Apple, Amazon, Barnes and Nobles) not only have the power to disrupt their revenue streams, but such disruptions can occur suddenly and capriciously. While apps presented a greater barrier to entry from other competitors than eBooks, and allowed for more features than eBooks, they were also more likely to get rejected from the appstores, and were much more expensive to produce.

Apple was due to make a major press release within the next 30 days, which could include further improvements (or impediments) in the authoring software and development process. The Kindle interactive book authoring solution was still in the very crude stages of development. John and Helen could reasonably expect significant improvements in the future if they chose to delay certain operational aspects of the product development to instead focus on content acquisition.

As it stood, the consultancy had already acquired quite a lot of content. Most of this content was in the form of educational intellectual property that included thousands of pages of rather timeless and proven textbooks as well as hundreds of hours of audio material that went with those textbooks. The material was in great shape, was already in digital form, and could — at least in theory - be sold as iPad, Kindle Fire, and Barnes and Nobles Nook eBooks largely 'as-is'. But, this content would really benefit from a few thousand hours of effort that would allow it to be massaged into highly optimized interactive eBooks that took advantage of the enormous visual and audio capabilities of the iPad, Kindle Fire, and Barnes and Nobles Nook. The Farrells also already had graphic artists designing young children's stories and educational workbooks for young children. But platform capabilities continued to change rapidly. Just a week prior, Apple had announced its new iPad device. So, an argument could be made to hold off on releasing their content until platform features sets were more stable. Alternatively, it might also make sense to release less polished versions rapidly, thereby capturing some initial revenues and establishing market position.

The Farrells viewed as crucial the following elements of their decision:

1) Should they switch from the more expensive App model to focus exclusively on the less expensive to produce interactive books, even though there are both more feature limitations and less barriers to entry in that type of product line?

If features were not a huge concern, and currently they were not, it seemed as if the answer might be to switch to the interactive books. It was likely that as more time passed, more widgets would become available, allowing interactive books to provide a more app like experience. On the other hand, if they waited until more advanced apps had already established themselves in the marketplace, they might find it nearly impossible to break in.

2) Do they provide their products for Apple's iPad/iPhone, Amazon's Kindle, Barnes and Nobles' Nook, other readers?

It was evident that providing their products for all available distribution channels would allow the company to maximize its market share and provide more revenues. It would, however, complicate production and increase the development time, although the impact would be reduced if only interactive books were developed.

3) How should they price their products? $\$ 0.99$ for maximum downloads? $\$ 14.99$ for maximum margin? Free but Ad supported? 


\section{Sanchez-Murphy, Murphy, \& Gill}

Over the previous year, the average purchase price per app download had increased by $\$ 1$. Taking into consideration investment costs, the company would be more likely to price its books in the $\$ 1.99$ - \$2.99 range. Many mobile application users felt that ad supported free apps are annoying to deal with, but would they feel comfortable buying an app if they could not try it first? And how would this equation change in the eBook and eTextbook space?

4) Should they invest in direct market campaigns with an unproven ROI?

Due to the prolonged negative cash flow carry, the company has decided to hold off on making an investment until multiple products were ready for release. At that point, they had planned to engage a PR to develop a formal marketing campaign. Given the increasing drain on their cash flow, however, would it be wise to make such an investment before signals of initial interest from the marketplace had been received?

5) Should they retain full time employees or outsource everything?

If successful, the consultancy would need its existing employees and, perhaps, new ones to build its stream of products. Since the ability to create apps and eBooks was in high demand, it would be difficult and expensive to add people. On the other hand, keeping existing staff placed a drain on the company's already strained cash flow resources.

6) Do they author and release products now, or continue to focus on content acquisition while the authoring platforms for the major distribution channels continue to mature over this year?

How effectively they addressed these questions would determine the fate of the company. 


\section{Exhibit 1: Examples of Educational Apps}

Art

Brushes: Users experiment with color and brush texture to paint original artwork.

Art History Tool: This app tests your knowledge using flash cards questions regarding artist, medium, title, etc.

Music

Classical Guitar: User can play music using a six-stringed guitar.

Ear Trainer Lite: Tests users "ear" using a game/quiz style.

Math

Alge-Bingo: Teaches basic to multi-step algebra equations through playing bingo.

Time, Money \& Fractions On-Track: Teaches time, money, and fractions through various exercises.

\section{Science}

Frog Dissection: Virtually simulates the experience of a frog dissection.

Solar Walk: Explore the solar system using 3-D graphics

\section{Language Arts}

Shakespeare: Complete works of Shakespeare

StoryKit: Make your own storybook 


\section{Exhibit 2: Helen's Pro and Con's List}

\begin{tabular}{|c|c|c|}
\hline$\overline{\text { Issue }}$ & Pros & Cons \\
\hline $\begin{array}{l}\text { Apps instead of } \\
\text { ebooks }\end{array}$ & Feature rich experience & More difficult to program \\
\hline $\begin{array}{l}\text { eBooks instead of } \\
\text { Apps }\end{array}$ & $\begin{array}{l}\text { Easier to program. iBooks author gives you the tem- } \\
\text { plates, so no programming in that regard. }\end{array}$ & $\begin{array}{l}\text { Very limited on features. Seems } \\
\text { right now there is audio, ques- } \\
\text { tions, and that's it. Not easy to } \\
\text { make picture books since it seems } \\
\text { to require chapters. }\end{array}$ \\
\hline iPad & $\begin{array}{l}\text { large screen, intuitive, a } 2 \text { year old can pretty much } \\
\text { pick it up and use it, lots of apps and ebooks, content is } \\
\text { easily transferred to iphone, apple app store very easy } \\
\text { to use. }\end{array}$ & $\begin{array}{l}\text { Expensive, and a little on the big } \\
\text { side, ie can't throw it in your purse }\end{array}$ \\
\hline iPhone & $\begin{array}{l}\text { Easy to use, lots of apps, very portable, ease of app } \\
\text { store, many free/cheap apps, service is good }\end{array}$ & small screen size, expensive \\
\hline Kindle fire & $\begin{array}{l}\text { Easy to use, many inexpensive apps, very portable, } \\
\text { good screen size, amazon app store easy to use, not too } \\
\text { pricey at } \$ 200\end{array}$ & $\begin{array}{l}\text { apps don't have as many of the } \\
\text { features as ios apps, can't always } \\
\text { transfer apps between phone and } \\
\text { device }\end{array}$ \\
\hline Nook & Good price point & $\begin{array}{l}\text { Not as many apps, can't always } \\
\text { transfer apps between phone and } \\
\text { device }\end{array}$ \\
\hline Multiple platforms & Capture more of the market share & More difficult to program \\
\hline Single Platform & $\begin{array}{l}\text { Focus and efficiency, once you have the routine down, } \\
\text { you can crank them out }\end{array}$ & $\begin{array}{l}\text { Limiting yourself to one market } \\
\text { can be an issue if the platform } \\
\text { rejects an app or ebook }\end{array}$ \\
\hline Free (ad supported) & More buyers & Finding ads \\
\hline download & Don't have to deal with ads, so easier for customers & Cost \\
\hline$\$ 0.99$ Price Point & More will buy due to low cost & very slim profits \\
\hline \$9.99 Price Point & Higher profit & $\begin{array}{l}\text { Due to the cost, customers expect } \\
\text { more and are more likely to pro- } \\
\text { vide negative feedback }\end{array}$ \\
\hline $\begin{array}{l}\text { Market campaigns } \\
\text { with unproven ROI }\end{array}$ & May garner higher sales & expensive / uncertain \\
\hline $\begin{array}{l}\text { Full time employ- } \\
\text { ees }\end{array}$ & Hire trusted people & $\begin{array}{l}\text { With taxes and insurance can be } \\
\text { expensive }\end{array}$ \\
\hline Outsource & Easy to find, easy to use & $\begin{array}{l}\text { Can work be done correctly with- } \\
\text { out supervision, trust }\end{array}$ \\
\hline $\begin{array}{l}\text { Release apps now } \\
\text { as completed }\end{array}$ & $\begin{array}{l}\text { Start getting in cash now, able to see if there will be } \\
\text { sufficient ROI }\end{array}$ & Others may catch on and copycat \\
\hline $\begin{array}{l}\text { Hold \& release } \\
\text { apps all at once }\end{array}$ & Less likely for copycats, advertise more efficiently & $\begin{array}{l}\text { Someone can beat you to the } \\
\text { punch }\end{array}$ \\
\hline
\end{tabular}




\section{Exhibit 3: Devices}

\begin{tabular}{|l|l|l|l|}
\hline Device & $\begin{array}{l}\text { Retail Price } \\
\text { Point }\end{array}$ & $\begin{array}{l}\text { Most recent device sales fig- } \\
\text { ures }\end{array}$ & Apps on respective markets \\
\hline iPad & 729.99 & $\begin{array}{l}\text { 55 million units sold to date accord- } \\
\text { ing to analysts, as of 03/03/12. }\end{array}$ & 200,000 \\
\hline iPhone & 626.95 & $\begin{array}{l}100 \text { Million units sold since } \\
03 / 02 / 11 .\end{array}$ & $\begin{array}{l}385,000 \text { estimated (Apple an- } \\
\text { nounced 585,000 apps, 200,000 } \\
\text { of which were for specifically for } \\
\text { iPads). }\end{array}$ \\
\hline Kindle Fire & 199 & $\begin{array}{l}\text { 3 Million sold to date as of 12/15/11 } \\
\text { according to PC World. }\end{array}$ & \\
\hline Nook Color & 169 & 3 Million as of 03/28/11. & \\
\hline
\end{tabular}

Source: compiled by case writers from various web sources 


\section{Exhibit 4: Publishing eBooks}

Apple, Amazon, and Barnes and Noble all charge a commission around 30\% to 40\% for selling ebooks through their respective stores. They all allow customers to rate and criticize the ebooks for sale on their markets. However, there can be some slight variation in how a given ebook is authored depending on which market it is going to be sold on, and which device it is going to support.

iBooks and Kindle ebooks can be authored in a number of different ways, but there are at least three widely used tools to this end: iBooks Author, Adobe InDesign, and Calibre. iBooks Author is a software suite specifically for eBook authoring in the iBooks environment (and, according to Apple terms, only for the iBooks environment). Calibre is a third party free software tool that is typically meant for ebook conversion typical in private ebook consumption but can also be used for much of the process of authoring commercially published ebooks.

To download the iBook authoring software, one has to start a developer account with Apple, specifically for iBook development. Registration is free, as well as the software for author and publisher, which the registrant can download once registered. The "Author" software is the actual document creation tool, and "Publisher" is the software required to validate and submit the iBook to the Apple iBook store.

The software handles text gracefully in both portrait and landscape orientations, but any graphicsintensive presentation will have to spend time working in portrait and landscape. Aside from that, the formatting tools are similar to many desktop publishing software suites you may have used. Rich text controls, image and other multimedia insertion, and device-enabled preview allow you to get an accurate idea of how your eBook will look on the iPad devices. You can also insert advanced HTML 5 widgets, though you'll have to test sufficiently with your device to make sure that they work within the iBooks environment.

Calibre is an amazingly powerful and somewhat flexible tool to convert existing document formats into iBooks. However, Calibre does not automatically make an ebook ready to submit to iTunes, per se, depending on the source material. Apple will reject any iBook if certain HTML tags cannot be applied (img alt tags, for example).

Other software such as Adobe InDesign can also be used to create eBooks, although like Calibre, the eBooks will not necessarily be in the most optimized end format for Apple iBooks distribution. Unlike iBooks Author and Calibre InDesign carries a hefty price tag.

Calibre and InDesign can also be used to prepare Kindle ebooks, but the ebooks still need to be ran through Amazon's publishing service in order to be available on the Kindle bookstore. 


\section{Exhibit 5: Helen's eBook Authoring Tool Pro and Con's List}

\begin{tabular}{|c|c|c|c|}
\hline InDesign & $\begin{array}{l}\text { Very powerful publishing soft- } \\
\text { ware with a lot of cross- } \\
\text { compatibility with Adobe soft- } \\
\text { ware. Most advanced WISY- } \\
\text { WIG publishing software that is } \\
\text { not proprietarily locked into one } \\
\text { platform or another. }\end{array}$ & $\begin{array}{l}\text { Expensive software with learning } \\
\text { curve, no specific tailoring per plat- } \\
\text { forms by default. }\end{array}$ & $\begin{array}{l}\$ 699.00 \text { re- } \\
\text { tail. }\end{array}$ \\
\hline $\begin{array}{l}\text { iBooks Au- } \\
\text { thor }\end{array}$ & $\begin{array}{l}\text { Free software, relative ease-of- } \\
\text { use. HTML widget support. } \\
\text { Separate customization possi- } \\
\text { ble for landscape and portrait, in } \\
\text { terms of image distribution and } \\
\text { page composition. }\end{array}$ & $\begin{array}{l}\text { Proprietary licensing technically re- } \\
\text { quires that you distribute the content } \\
\text { on itunes / iBook store and not in oth- } \\
\text { er platforms. The landscape/portrait } \\
\text { division of presentation styles some- } \\
\text { times requires specific, forked design } \\
\text { work to accomodate both orientations. } \\
\text { Template choice is limited, control } \\
\text { over presentation layer is nowhere } \\
\text { near the level it would be with Kindle- } \\
\text { specific HTML5 CSS3 capable format } \\
\text { (KF8). }\end{array}$ & Free \\
\hline Calibre & $\begin{array}{l}\text { Free software. It can automati- } \\
\text { cally convert many different } \\
\text { document formats (Word proc- } \\
\text { essor files, PDFs, HTML files, } \\
\text { etc) to eBook format automati- } \\
\text { cally, with some degree of per- } \\
\text { platform/device customization } \\
\text { parameters. }\end{array}$ & $\begin{array}{l}\text { Automatic conversion is itself a con, } \\
\text { as you must make alterations either to } \\
\text { your source files or outputted ePub } \\
\text { files for some changes. It is quite } \\
\text { powerful, but designed primarily for } \\
\text { private consumer use. There is no } \\
\text { guarantee any commercial ebook re- } \\
\text { tailer platform will successfully vali- } \\
\text { date the output (for example, iBooks } \\
\text { will reject image/html conversions } \\
\text { without "Alt" tags). }\end{array}$ & Free \\
\hline $\begin{array}{l}\text { Kindle Pub } \\
\text { Tools }\end{array}$ & $\begin{array}{l}\text { HTML5 / CSS support; allegedly } \\
\text { greater control of content pres- } \\
\text { entation layer than EPUB due to } \\
\text { HTML } 5\end{array}$ & $\begin{array}{l}\text { Content is proprietary, for use in Kin- } \\
\text { dle platform; file format is Kindle For- } \\
\text { mat } 8 \text { (KF8) rather than EPUB. No } \\
\text { platform tools or software yet per se, } \\
\text { except conversion tools offered by } \\
\text { Amazon, a Preview wizard, and In- } \\
\text { Design plugins. }\end{array}$ & Free \\
\hline $\begin{array}{l}\text { By Hand } \\
\text { Dev }\end{array}$ & $\begin{array}{l}\text { Greatest possible control over } \\
\text { EPUB presentation style and } \\
\text { cross-compatibility (at the code } \\
\text { level). Any particular proprie- } \\
\text { tary validation issue per plat- } \\
\text { form can conceivably be re- } \\
\text { solved at the code level. }\end{array}$ & $\begin{array}{l}\text { By definition, it is the least automated, } \\
\text { most skill-requisite method. }\end{array}$ & Free \\
\hline
\end{tabular}

